\title{
The impact of intensive care unit diaries on patients' and relatives' outcomes: a systematic review and meta-analysis
}

Bruna Brandao Barreto ${ }^{1 *}$ (D), Mariana Luz ${ }^{1}$, Marcos Nogueira de Oliveira Rios ${ }^{1}$, Antonio Alberto Lopes ${ }^{2,3,4}$ and Dimitri Gusmao-Flores ${ }^{1,2,3,4,5}$

\begin{abstract}
Background: Memory gaps in intensive care unit (ICU) survivors are associated with psychiatric disorders. The ICU diaries improve the patient's factual memory of the ICU, but it is not clear if they reduce the incidence of psychiatric disorders in patients and relatives after hospital discharge. The aim of this study is to evaluate the literature on the effect of ICU diaries for patients admitted in ICU and their relatives.

Methods: Two authors independently searched the online databases PubMed, OVID, Embase, EBSCO host, and PsycINFO from inception to July 2019. Studies were included if the intervention group (ICU diary) was compared with a group with no diaries and the sample was comprised patients $\geq 18$ years old admitted in the ICU for more than $24 \mathrm{~h}$ and their relatives. Randomized clinical trials, observational studies, letter with original data, and abstracts were included, irrespective of the language. The search was not limited by any specific outcome. Review articles, commentaries, editorials, and studies without a control group were excluded. Structured tools were used to assess the methodological quality ("Risk Of Bias In Non-randomized Studies of Interventions (ROBINS-I)" for cohort studies and the "Cochrane Risk of Bias tool" for included RCTs and before/after studies). A random-effects model was employed considering the anticipated variability between the studies.
\end{abstract}

Results: Seven hundred eighty-five titles were identified for screening. Two additional studies were selected after a reference search, and after a full-text review, a total of 12 studies were included. When pooling the results, ICU diary was associated with lower risk of depression (RR $0.41,95 \% \mathrm{Cl} 0.23-0.75)$ and better quality of life (10.3 points higher in SF-36 general health score, 95\% Cl 0.79-19.8), without a decrease in anxiety or post-traumatic stress disorder (PTSD). For the relatives receiving an ICU diary, there was no difference in the incidence of PTSD, anxiety, or depression.

Conclusion and relevance: This systematic review and meta-analysis supports the use of ICU diaries to reduce the risk of depression and preserve the quality of life of patients after ICU admission. ICU diaries do not seem to have any beneficial effect on the relatives of the patients.

Trial registration: PROSPERO, CRD42019136639

Keywords: ICU diary, Post-traumatic stress disorder, Anxiety, Depression, Quality of life

\footnotetext{
* Correspondence: brunab_barreto@yahoo.com.br

'Intensive Care Unit, Hospital da Mulher, Rua Barão de Cotegipe, 1153, Roma,

Salvador, Bahia 40411-900, Brazil

Full list of author information is available at the end of the article
}

(C) The Author(s). 2019 Open Access This article is distributed under the terms of the Creative Commons Attribution 4.0 International License (http://creativecommons.org/licenses/by/4.0/), which permits unrestricted use, distribution, and reproduction in any medium, provided you give appropriate credit to the original author(s) and the source, provide a link to the Creative Commons license, and indicate if changes were made. The Creative Commons Public Domain Dedication waiver (http://creativecommons.org/publicdomain/zero/1.0/) applies to the data made available in this article, unless otherwise stated. 


\section{Introduction}

Patients surviving the intensive care unit (ICU) frequently experience memory gaps and unpleasant recall after ICU discharge [1]. These memory changes are often associated with the development of symptoms of anxiety, depression, and post-traumatic disorder [1] that impacts negatively on the health-related quality of life [2-5]. The need to cope with negative emotions and symptoms, the presence of delirium, in addition to periods under sedation and sleep deprivation during critical illness are factors that may predispose to these phenomena [6].

In 1999, Backman and Walther published what seems to be the first report of the use of ICU diaries as a way to concretize what happened to the patients during ICU care and help them to understand the chain of events during the ICU stay [7]. The use of ICU diaries has been proposed as a tool to help fill the patient's memory and reduce the incidence of psychiatric disorders in patients and their relatives after ICU discharge.

Clinical trials have been conducted in order to evaluate the impact of ICU diaries on the development of psychiatric disorders and on quality of life [8,9], and a meta-analysis summarized these findings suggesting a potential benefit with these approaches [10]. Since the publication of this meta-analysis, new studies were published, including three randomized trials [11-13].

The aim of this study is to reevaluate the current literature on the effect of ICU diaries for patients admitted in the ICU and their relatives, giving also a detailed description of the diary structure, healthcare impression on writing diaries, and patients' feedbacks on receiving an ICU diary.

\section{Methods}

Preferred Reporting Items for Systematic reviews and Meta-Analysis (PRISMA) guidelines were used in the preparation of this review (the checklist can be found in Additional file 1). The protocol was prospectively published on the International Prospective Register of Systematic Reviews (PROSPERO)—CRD42019136639.

\section{Search strategy}

Two authors (BBB, ML) independently searched the online databases PubMed, OVID, Embase, EBSCO host, and PsycINFO from inception to July 2019 using Medical Subject Headings with search terms aiming to capture those publications which contained variations of "intensive care" and "ICU diary." Full search strategies can be found in Additional file 2.

This search was supplemented by reviewing all references of relevant articles and searches in Google Scholar. The automatic alert system of PubMed was used to identify studies published during the process of the analysis of the results and writing of the manuscript. Any disagreement was solved by a discussion or review by a third author (DGF).

\section{Study selection}

Articles were included if they were original research where an ICU diary intervention group was compared with a group without diaries. Randomized controlled trials (RCT), prospective or retrospective cohort, beforeand-after study, letter with original data, case-control studies, and abstracts of congress were all included, irrespective of the language in which the study was written. The studies were included regardless of the outcomes studied. If the data needed could not be extracted, an email was sent to the authors in order to obtain the information. Studies with samples of adult patients $(\geq 18$ years old) admitted to an ICU for more than $24 \mathrm{~h}$ and their family members were eligible for the review.

Studies were excluded if they were review articles, commentaries, and editorials or when the key results were not found even after attempting contact with the authors.

\section{Data extraction}

A structured template was used for the extraction of data from the included studies. Data collected included study design, location, publication year, length of followup, and study-specific outcomes assessed with respective scales and cutoffs used (when appropriate). These data were independently extracted by three authors (BBB, ML, MNR) and compared for concordance.

For pooling the results, data from individual studies were extracted as dichotomous outcomes and as means, difference of means, or median when appropriate. The latter format was extracted because important outcomes, such as quality of life or intensity of psychological symptoms (e.g., anxiety, depression, and post-traumatic stress symptoms), can only be measured as mean or median using appropriate scales or scores.

Due to the difference of the time of follow-up (with some studies having multiple time points), the outcomes regarding the first follow-up after the intervention were extracted.

\section{Risk of bias}

Structured tools were used to assess the methodological quality of the included studies. This included the Risk Of Bias In Non-randomized Studies of Intervention (ROBINS-I) [14, 15] for cohort studies and the "Cochrane Risk of Bias tool" [15] for included RCTs and before-andafter studies. Three authors (BBB, ML, MNR) independently assessed the risk of bias of the included studies, and any disagreement was solved by a discussion or a review by a fourth author (DG-F). The ROBINS-I tool is based on the Cochrane Risk of Bias tool for randomized trials, in which risk of bias is assessed within specified bias domains 
(confounding, selection of participants into the study, classification of interventions, deviations from intended interventions, missing data, measurement of outcomes, selection of the reported result). For the "Cochrane Risk of Bias tool," a study summarized as with a high risk of bias was judged to have a "high risk of bias" for one or more key domains.

\section{Statistical analysis}

Data analysis was performed using the "meta" and "metafor" packages of the R software [16] version 3.5.1. Risk ratios (RRs) and 95\% confidence intervals (CIs) were used, as summary statistics for studies with binary outcomes and means for studies with continuous outcomes. The studies with binary outcomes were integrated with the Mantel-Haenszel method, and for studies with continuous variables, the inverse-variance method was used for calculating the weighted average. We used the Hartung-Knapp adjustment for random-effects model [17] and the SidikJonkman estimator for tau. The Hartung-Knapp-SidikJonkman method was chosen for random-effects metaanalysis because it outperforms the DerSimonian and Laird approach when the number of studies included in the meta-analysis is small (less than 20 studies), even when studies of different sizes are combined $[18,19]$. Statistical heterogeneity was quantified with the $I^{2}$ statistics. A random-effects model was employed considering the anticipated variability between the trials regarding patient samples and medical interventions. The 95\% prediction interval was also calculated $[20,21]$ to estimate where the true effects are to be expected for $95 \%$ of studies that might be conducted in the future. A two-tailed $p$ value of less than 0.05 was considered statistically significant.

For studies in which the mean value was presented without standard deviation, we estimated the standard deviation using the $p$ value and group sample size to calculate the $t$ value using the RevMan Calculator available at the Cochrane Training website [22]. For studies in which data were presented as the median and interquartile range (IQR), we estimated the mean and standard deviation from these values [23-25]. Funnel plots and Egger test were used to test for detecting small-study effects. The $\mathrm{R}$ script is available in Additional file 3.

Those studies that reported outcomes that could not be pooled, because they were unique to that particular study, were presented in a qualitative analysis.

\section{Results}

We identified 785 individual titles and abstracts for screening. One hundred fifty-nine were selected for a fulltext review of which 10 satisfied all inclusion and exclusion criteria $[8,9,11,13,26-31]$. Two additional studies were included following a search of references [12, 32], bringing the total number of included studies to 12 .
Figure 1 outlines the flowchart of the search, with respective reasons for study exclusion. Of the 12 included trials, 6 were RCTs $[8,9,11-13,30], 2$ were before-and-after studies $[28,32]$, and the remaining 4 being an observational cohort design [26, 27, 29, 31]. The measurement of agreement of study selection is presented in Additional file 2. There was no disagreement on data extraction. Characteristics of the included studies are summarized in Table 1, and the structure of the diaries used in the studies is presented in Additional file 2.

\section{Overview of methodological quality}

All RCTs and before-and-after studies were assessed as high risk of bias (the detailed evaluation is presented in Additional file 2: Figure S2). All the cohort studies were assessed as moderate or serious risk of bias according to ROBINS-I (Table 1). There was no disagreement on the final judgment of the risk of bias.

\section{The effect of ICU diaries on patients' outcomes Post-traumatic stress disorder}

Six studies investigated the effect of ICU diaries on PTSD symptoms and diagnosis. Four of them are RCT $[8,11-13]$. The scales used in the evaluation were Post-traumatic Stress Symptoms (PTSS-14) screening tool, Impact of Event Scale-Revised (IES-R), and PTSD Diagnostic Scale (PDS). Both the PTSS-14 and IES-R scales were dichotomized in order to diagnose PTSD (Additional file 2: Table S1).

Severity of symptoms measured by mean/median IES-R and PTSS-14 Jones et al. [8] reported a reduction in the PTSS-14 scores for those with severe symptoms of PTSD (a decrease in 23 points in PTSS-14 for those with 45 points or more, $p=0.04$ ). Garrouste-Orgeas et al. [28] reported a reduction in PTSD symptoms with ICU diaries measured by mean IES-R score. The remaining studies [11$13,29]$ did not find any difference in the severity of symptoms between those who received or not the ICU diary.

PTSD diagnosis Jones et al. [8] reported a protective effect of ICU diaries regarding PTSD diagnosis. By contrast, the Glimelius Petersson study [29] reported an increase in PTSD cases in those who received diaries. The difference in PTSD between the groups that received and not received an ICU diary was not observed in the remaining studies [11-13, 28] (Fig. 2).

\section{Depression}

Six studies investigated the effect of ICU diaries on depression diagnosis and severity of symptoms $[9,11,12$, 28, 32]. Four of them are randomized controlled trials $[9,11-13]$. All studies used the same scale to evaluate and diagnose depression-the Hospital Anxiety and Depression Scale (HADS) - but different cutoff points were 


\section{Flow Diagram}
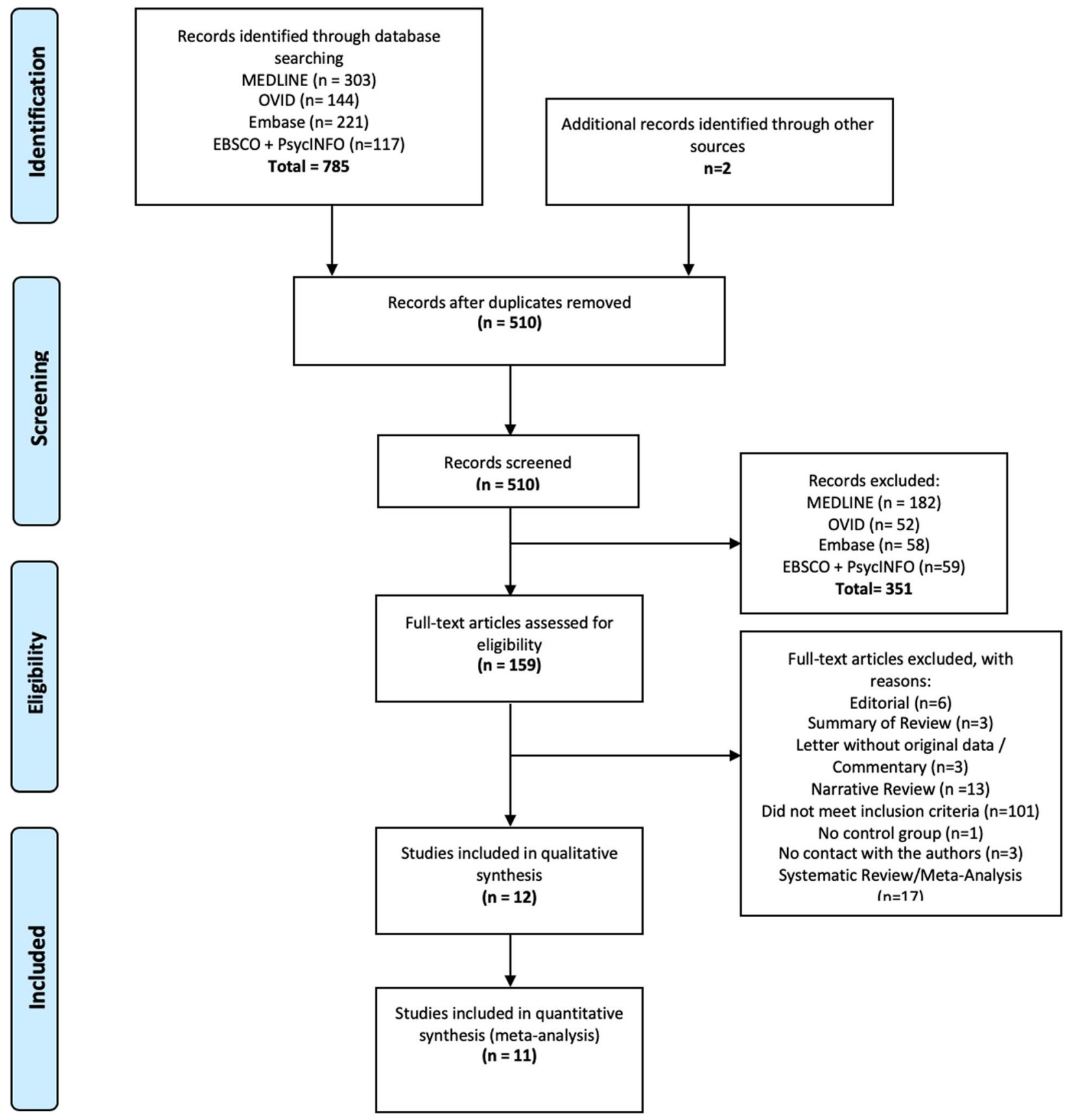

Fig. 1 Flowchart of the systematic review

used to dichotomize the variable (Additional file 2: Table S2).

Severity of depressive symptoms measured by mean/ median HADS Two RCTs reported a decrease of depressive symptoms in patients that received the ICU diary [9, 11]. Nielsen et al. [12] and Garrouste-Orgeas et al. [28] did not report HADS score as a continuous variable. Garrouste-Orgeas et al. [13] did not find any difference between the groups. Fukuda et al. [32] reported that receiving the ICU diary decreased the depressive symptoms (from $8.6 \pm 5.0$ to $7.2 \pm 4.3$ points in HADS, $p=0.003$ ) only in patients with distorted memories of the ICU admission (Additional file 2: Figure S2). 
Table 1 Characteristics of studies included in the meta-analysis

\begin{tabular}{|c|c|c|c|c|c|c|c|c|c|}
\hline Author & Year & Design & Subjects & Sample size & Country & Diary delivery & Follow-up & Tools & Risk of bias \\
\hline $\begin{array}{l}\text { Garrouste-Orgeas } \\
\text { et al. [13] }\end{array}$ & 2019 & $\mathrm{RCT}$ & $\begin{array}{l}\text { Patients and } \\
\text { relatives }\end{array}$ & 657 & France & ICU discharge & $\begin{array}{l}90 \text { days after } \\
\text { ICU discharge }\end{array}$ & HADS, IES-R & High \\
\hline Nielsen et al. [12] & 2019 & $\mathrm{RCT}$ & $\begin{array}{l}\text { Patients and } \\
\text { relatives }\end{array}$ & 116 & $\begin{array}{l}\text { Western } \\
\text { Denmark }\end{array}$ & ICU discharge & $\begin{array}{l}90 \text { days after ICU } \\
\text { discharge }\end{array}$ & $\begin{array}{l}\text { HADS, PTSS- } \\
14, \text { SF-36 }\end{array}$ & High \\
\hline $\begin{array}{l}\text { Kredentser et al. } \\
\text { [11] }\end{array}$ & 2018 & $\mathrm{RCT}$ & Patients & 58 & Canada & $\begin{array}{l}30 \text { days after } \\
\text { ICU discharge }\end{array}$ & $\begin{array}{l}90 \text { days after ICU } \\
\text { discharge }\end{array}$ & HADS, IES-R & High \\
\hline Jones et al. [30] & 2012 & $\mathrm{RCT}$ & Relatives & 36 & $\begin{array}{l}\text { Sweden and the } \\
\text { UK }\end{array}$ & $\begin{array}{l}30 \text { days after } \\
\text { ICU discharge }\end{array}$ & $\begin{array}{l}90 \text { days after ICU } \\
\text { discharge }\end{array}$ & PTSS-14 & High \\
\hline Jones et al. [8] & 2010 & $\mathrm{RCT}$ & Patients & 352 & $\begin{array}{l}\text { Denmark, Italy, } \\
\text { Norway, Portugal, } \\
\text { Sweden, and the } \\
\text { UK }\end{array}$ & $\begin{array}{l}30 \text { days after } \\
\text { ICU discharge }\end{array}$ & $\begin{array}{l}90 \text { days after ICU } \\
\text { discharge }\end{array}$ & PDS, PTSS-14 & High \\
\hline Knowles et al. [9] & 2009 & $\mathrm{RCT}$ & Patients & 36 & UK & $\begin{array}{l}30 \text { days after } \\
\text { ICU discharge }\end{array}$ & 3 weeks & HADS & High \\
\hline Fukuda et al. [32] & 2015 & $\begin{array}{l}\text { Before- } \\
\text { and-after }\end{array}$ & Patients & 40 & Japan & $\begin{array}{l}1 \text { week after ICU } \\
\text { discharge }\end{array}$ & $\begin{array}{l}10 \text { days after the post-ICU } \\
\text { survey and prior to the } \\
\text { discharge from the } \\
\text { hospital }\end{array}$ & HADS, ASDS & High \\
\hline $\begin{array}{l}\text { Garrouste-Orgeas } \\
\text { et al. [28] }\end{array}$ & 2012 & $\begin{array}{l}\text { Before- } \\
\text { and-after }\end{array}$ & $\begin{array}{l}\text { Patients and } \\
\text { relatives }\end{array}$ & 143 & France & ICU discharge & $\begin{array}{l}3 \text { months (HADS/PDEQ), } \\
12 \text { months (IES-R) }\end{array}$ & $\begin{array}{l}\text { HADS, PDEQ, } \\
\text { IES-R }\end{array}$ & High \\
\hline $\begin{array}{l}\text { Åkerman and } \\
\text { Langius-Eklof [26] }\end{array}$ & 2018 & Obs & Patients & 419 & Sweden & Unclear & 2,6 , and 12 months & 3-set 4P & Moderate \\
\hline $\begin{array}{l}\text { Glimelius Petersson } \\
\text { et al. [29] }\end{array}$ & 2015 & Obs & Patients & 96 & Sweden & ICU discharge & 2 months & PTSS-14 & Serious \\
\hline $\begin{array}{l}\text { Svenningsen } \\
\text { et al. [31] }\end{array}$ & 2014 & Obs & Patients & 360 & Denmark & $\begin{array}{l}1 \text { week after } \\
\text { ICU discharge }\end{array}$ & 6 months & SF-36 & Serious \\
\hline Backman et al. [27] & 2010 & Obs & Patients & 499 & Sweden & $\begin{array}{l}\text { Hospital } \\
\text { discharge }\end{array}$ & 6 months & SF-36 & Moderate \\
\hline
\end{tabular}

RCT randomized controlled trial, ICU intensive care unit, UK United Kingdom, Obs observational cohort, ROBINS-I Risk Of Bias In Non-randomized Studies of Interventions, HADS Hospital Anxiety and Depression Scale, PDEQ Peritraumatic Dissociative Experiences Questionnaire, PTSS-14 Post-traumatic Stress Symptoms screening tool, SF-36 Modified Medical Outcomes Short Form, IES-R Impact of Event Scale-Revised, ASDS Acute Stress Disorder Scale, PDS Post-traumatic Stress Disorder Diagnostic Scale

Depression diagnosis The study of Garrouste-Orgeas et al. [13] did not present the incidence of depression in patients. The point estimates of all remaining studies were consistent by showing a decrease in the risk of depression with the use of ICU diaries, but the confidence intervals crossed the null value. When pooling the results, a relative reduction of $69.0 \%$ in the risk of depression associated with ICU diaries was observed (Fig. 3).

\section{Anxiety}

Six studies investigated the effect of ICU diaries on anxiety diagnosis and severity of symptoms $[9,11-13,28$, 32]. Four of them are randomized controlled trials [ 9 , 11-13]. As in the studies of depression, all studies used the same scale to evaluate and diagnose anxiety-the Hospital Anxiety and Depression Scale (HADS) - but different thresholds were used to dichotomize the variable (Additional file 2: Figure S2).

Severity of symptoms of anxiety measured by mean or median HADS One RCT reported a decrease of anxiety symptoms in patients that received the ICU diary. Nielsen et al. [12] and Garrouste-Orgeas et al. [28] did not report HADS score as a continuous variable. Knowles and Tarrier [9] and Garrouste-Orgeas et al. [13] did not identify any difference in HADS scores between patients who received or not an ICU Diary. Fukuda et al. [32] found a decrease in HADS score (from $7.1 \pm 3.8$ to $5.7 \pm 2.7$ points, $p=0.011$ ) only in patients with distorted memories (Additional file 2: Figure S2).

Anxiety diagnosis The study of Garrouste-Orgeas et al. [13] did not present the incidence of anxiety in patients. Only one study showed a decrease of anxiety diagnosis for patients receiving an ICU diary [11]. When pooling all the results, there was no difference of anxiety between patients that received an ICU diary and those who did not (Fig. 3).

\section{Quality of life}

Three studies evaluated the impact of ICU diaries on quality of life using the Modified Medical Outcomes Short Form (SF-36) [12, 27, 31]. Only one of them was a RCT, and it did not show a difference between ICU diary and no diary in any of the domains of the SF-36 at 3 months of follow-up [12]. In the Bäckman et al. study [27], patients who received a diary had a higher mean 


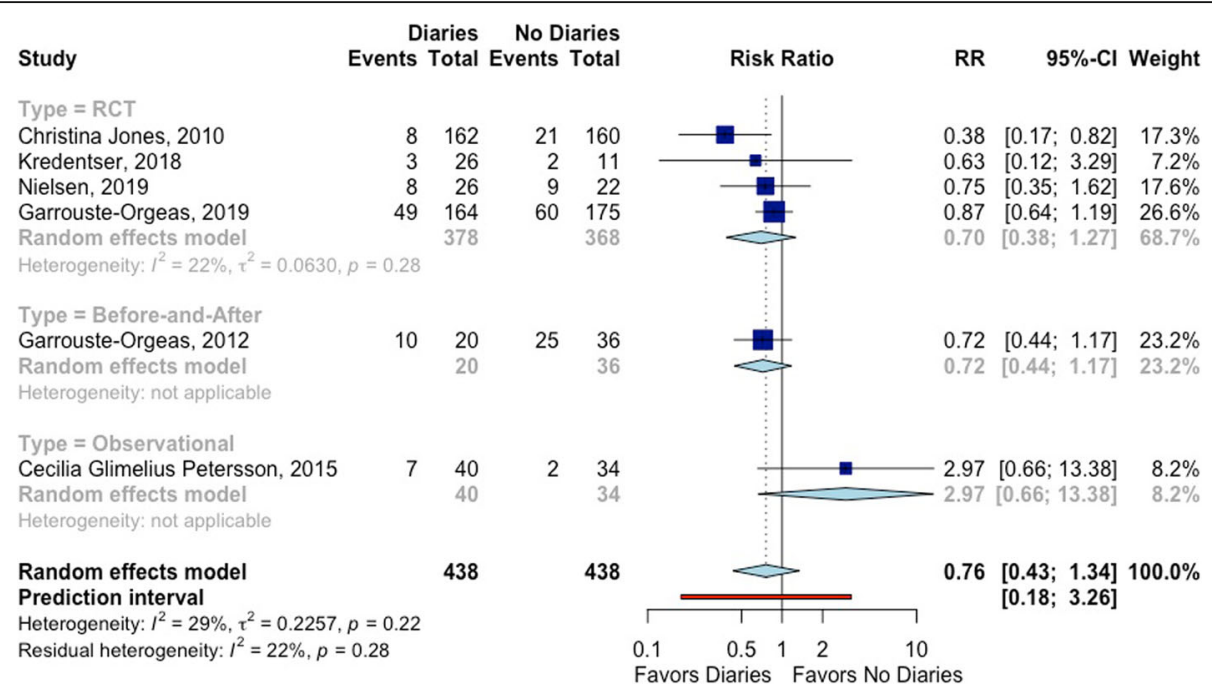

Fig. 2 The effect of ICU diaries on post-traumatic stress disorder in patients

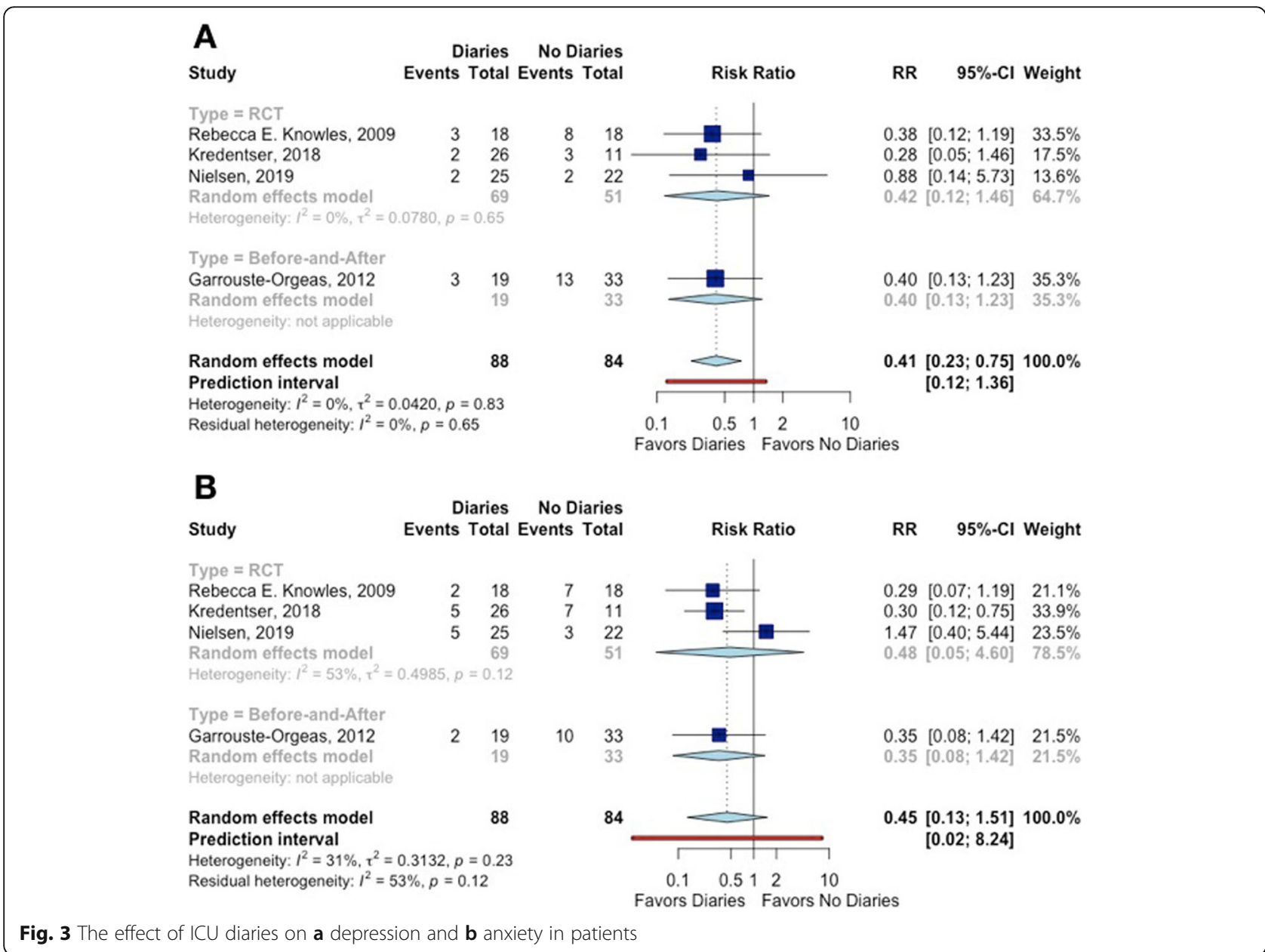


score for the global health $(\mathrm{GH})$ and vitality (VT) domains of the SF-36 at 6 months. Svenningsen et al. [31] reported an improvement only in the $\mathrm{GH}$ subsection of the SF-36 at 6 months (mean values of other domains were not presented). We pooled only $\mathrm{GH}$ scores from SF-36 (Fig. 4).

\section{The effect of ICU diaries on outcomes of the patient's relatives}

Four studies evaluated the effect of ICU diaries on the family's PTSD [12, 13, 28, 30]. One study reported no difference between the group that received or not the ICU diary [13]. The remaining three studies showed a decrease in PTSD incidence, but with a low precision of estimates. When pooling the results, there were no differences in the incidence of PTSD between those who received the ICU diary and those who did not.

Three studies investigated the impact of ICU diaries on depression and anxiety among relatives [12, 13, 28]. Only Garrouste-Orgeas et al. [28] reported an improvement in anxiety (Fig. 5).

\section{Patients' impressions about receiving an ICU diary}

Seven studies reported patients' and relatives' feedbacks about receiving and reading the ICU diary $[8,9,11,12$, 26, 29, 32]. Mostly, patients felt that the diaries helped them to (1) connect their own memories to what actually happened during the ICU admission, (2) connect with their families as a way to confirm information presented on the diary or as a way to understand what they also have been through during ICU admission, and (3) improve perception of ICU care [32]. Also, the presence of photos was considered "good or very good," leading to a greater understanding of what it looked like in the ICU and how ill they had been [29].

\section{Small-study effect}

The studies that reported PTSD, anxiety, and depression outcomes for both patients and relatives were tested for small-study effect by the use of funnel plots. None of the funnel plots showed any evidence of a small-study effect. The $p$ values for Egger tests were $>0.05$ (Additional file 2: Figure S3 to S8).

\section{Discussion}

The results of this systematic review and meta-analysis show that patients treated in intensive care units who received a diary had a lower risk of depression and better health-related quality of life measured by the global health domain of the SF-36 than those who did not receive a diary. On the other hand, there were no differences in PTSD and anxiety in patients, and the intensity of symptoms of depression and anxiety of patients who receive ICU diaries was similar to those who did not receive it. For the relatives of the patients, the results did not show improvement of psychological sequelae with the use of ICU diaries.

Since the beginning of the year 2000 [33], the use of ICU diaries has been extensively studied as a tool to enhance recovery after ICU admission [9, 12, 27-29, 32-47]. However, in the review for the present meta-analysis, we observed that only the minority of studies on ICU diaries evaluated the incidence of psychiatric diseases using validated scales as outcomes. A meta-analysis published in 2015 [48] based on the data of only three randomized trials $[8,9,30]$ indicated that there was minimal evidence to support the effectiveness of ICU diary in improving psychological recovery after critical illness for patients, their caregivers, or family members. A more recent metaanalysis with studies published until 2017 included eight studies: the three trials $[8,9,30]$ from the previous metaanalysis [48], two time series [28, 32], and three observational studies $[27,29,31]$. Similarly to the present metaanalysis, ICU diary was associated with lower symptoms of anxiety and depression, but not with post-traumatic stress syndrome [10]. Since then, four new studies have been published including three randomized controlled trials on the subject [11-13], which were included in the current meta-analysis.

The analysis of the present study was mainly based on quantitative data studies. However, we identified qualitative data studies that deserve mentioning. We found 21 qualitative studies about the perceptions of patients, families, and healthcare workers on writing and receiving ICU diaries [7, 33-47, 49-53]. Families of the patients who wrote and/or read the ICU thought that diaries were important to enhance access to and assimilation of medical

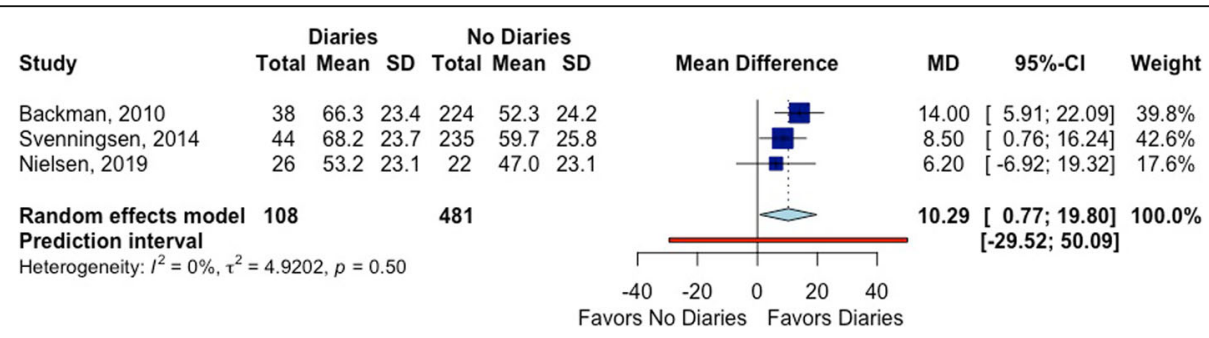

Fig. 4 The effect of ICU diaries on patients' quality of life (global health score of the SF-36) 


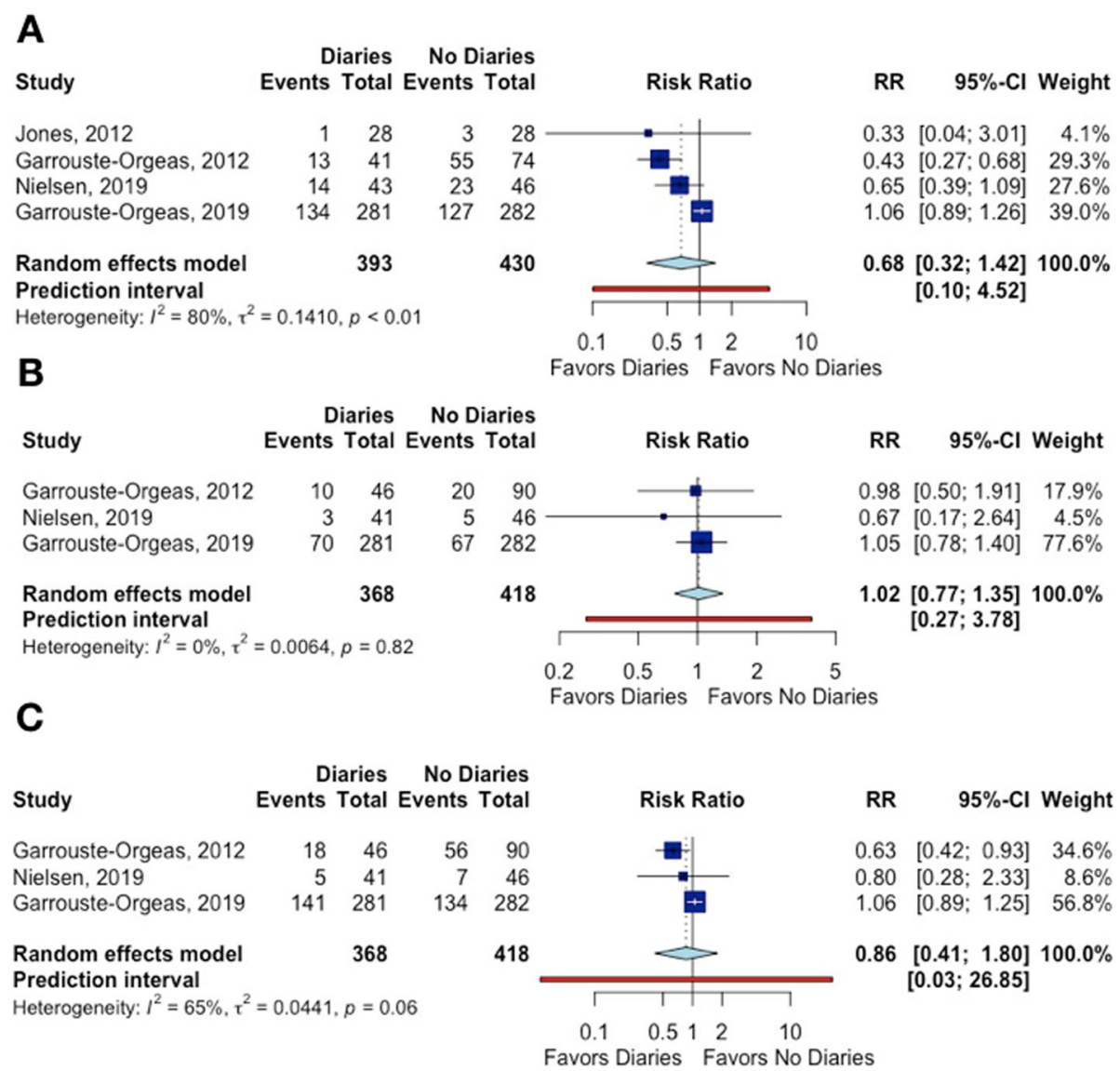

Fig. 5 The effect of ICU diaries on a post-traumatic stress disorder, $\mathbf{b}$ depression, and $\mathbf{c}$ anxiety in patients' relatives

information about the patient. They reported that the ICU diaries served as a channel of communication and approximation among family members in a tough moment of their lives and helped them to cope with overwhelming emotional experiences [40]. By writing and reading the diaries, family members could document their presence at the patient's side, express their love and affection, confide their intimate feelings, and struggled to maintain hope. Reading the diary also made the relatives aware that the staff saw patients as a living human being, and the time devoted by healthcare providers to the diary was seen by the family as a sign of consideration, emotional involvement, and empathy [40]. These feelings were identified in other studies [34, 41, 42], and even families of deceased patients thought that the diary offered consolation and helped them to cope bereavement [34, 44].

For healthcare providers, writing the diary helped to perceive the human dimension to their work and to improve communication with the families as an adjunct to oral communication [38]. Staff members also considered the reading of the diary beneficial by allowing a deeper knowledge of the patients as a human being through the eyes of their loved ones and broadening the perception of how hard ICU care can be on family members [38, 43]. It should be noted, however, that staff members also reported strong emotions and concerns about intrusion into the patients' and families' privacies related to diary writing and reading [38].

While the present study offers additional evidence about the role of ICU diary on psychiatric outcomes for patients and their relatives, methodological limitations cannot be ignored. One such potential limitation is the different designs of the selected studies (observational, before-andafter, randomized controlled trials), which are susceptible to different sources of bias. To reduce the influence of bias in the results, specific analyses by study type were performed. Variation among the studies in sample size, in the time of intervention, in tools used to diagnose PTSD, in the threshold used for the psychiatric diagnosis, and in follow-up duration was observed. A random-effects method was used to take into account these variations among studies. Despite the expected variations, the results of the $I^{2}$ statistic indicated a small heterogeneity in the association of ICU diary with some outcomes.

Another important consideration to be made refers to the recent study of Garrouste-Orgeas et al., the largest 
clinical trial on the topic so far [13]. This study was performed in 35 French ICUs, and they could not find any improvement in clinical outcomes with the use of the ICU diary. However, it is important to highlight that, despite the anticipation of a high mortality rate when calculating the sample size, a $50 \%$ rate of loss to follow-up may bias the association between the intervention and the outcome, as well as compromise the generalizability of the results.

Some strengths of the present systematic review also merit attention. By reviewing studies not included in a previously published meta-analysis, the present review expands the knowledge of the association between ICU diary and psychiatric outcomes in patients and their relatives [10]. In addition, we described the structure of diaries used in the studies, the reported workload associated with writing the diary, and the perception of the participants about receiving the diary (this information can be found in Additional file 2). In general, the patients considered the ICU diary an important tool to aid recovery and connection to their loved ones.

\section{Conclusions}

The results of the present meta-analysis suggest that ICU diaries may reduce the risk of depression and the negative effects of intensive care treatment on the quality of life of the patients. Considering the methodological limitations, the results of the meta-analysis support a beneficial effect of the ICU diaries by mitigating the psychological sequelae that are common after ICU admission. Adequately powered randomized trials should be developed to provide stronger evidence about the potential beneficial effects of ICU diaries on the psychiatric outcomes of patients and their relatives.

\section{Supplementary information}

Supplementary information accompanies this paper at https://doi.org/10. 1186/s13054-019-2678-0.

Additional file 1: PRISMA Checklist. It contains the Preferred Reporting Items for Systematic Reviews and Meta-Analysis (PRISMA) Checklist

Additional file 2: Supplementary Material. Contains the search strategy, results and supplementary tables and figures in addition to the ones presented in the manuscript.

Additional file 3: R Script (statistical analysis). It contains the R script used for analyzing data and creating forest plots for the meta-analysis.

\section{Abbreviations \\ ICU: Intensive care unit; PTSD: Post-traumatic stress disorder; RCT: Randomized controlled trial; ROBINS-l: Risk Of Bias In Non-randomized Studies of Intervention; HADS: Hospital Anxiety and Depression Scale; PDEQ: Peritraumatic Dissociative Experiences Questionnaire; PTSS-14: Post- traumatic Stress Symptoms screening tool; SF-36: Modified Medical Outcomes Short Form; IES-R: Impact of Event Scale-Revised; ASDS: Acute Stress Disorder Scale}

\section{Acknowledgements}

This study was financed in part by the Coordenação de Aperfeiçoamento de Pessoal de Nível Superior-Brasil (CAPES)-Finance Code 001.

\section{Authors' contributions}

BBB and DG-F conceived the study concept. BBB and ML searched the database. $B B B, M L$, and $M O N R$ reviewed the articles, assessed their quality, and extracted the variables. BBB and DG-F made the statistical analysis. BBB, ML, $A A L$, and DG-F wrote the manuscript. All authors agreed with the final version of the manuscript.

\section{Funding}

This research did not receive any specific grant from funding agencies in the public, commercial, or not-for-profit sectors.

Availability of data and materials

The datasets used and/or analyzed during the current study are available from the corresponding author on reasonable request.

Ethics approval and consent to participate

Not applicable

Consent for publication

Not applicable

\section{Competing interests}

The authors declare that they have no competing interests.

\section{Author details}

${ }^{1}$ Intensive Care Unit, Hospital da Mulher, Rua Barão de Cotegipe, 1153, Roma, Salvador, Bahia 40411-900, Brazil. Núcleo de Epidemiologia Clínica e Medicina Baseada em Evidências, Hospital Universitário Professor Edgard Santos, Universidade Federal da Bahia, Salvador, Brazil. ${ }^{3}$ Departamento de Medicina Interna e Apoio Diagnóstico, Faculdade de Medicina da Bahia, Universidade Federal da Bahia, Salvador, Brazil. ${ }^{4}$ Programa de Pós-Graduação em Medicina e Saúde, Faculdade de Medicina da Bahia, Universidade Federal da Bahia, Salvador, Bahia, Brazil. ${ }^{5}$ Intensive Care Unit, Hospital da Cidade, Salvador, Bahia, Brazil.

Received: 2 September 2019 Accepted: 18 November 2019

Published online: 16 December 2019

\section{References}

1. Jones C, Griffiths RD, Humphris G, Skirrow PM. Memory, delusions, and the development of acute posttraumatic stress disorder-related symptoms after intensive care. Crit Care Med. 2001;29(3):573-80.

2. Jones C, Skirrow P, Griffiths RD, Humphris G, Ingleby S, Eddleston J, Waldmann C, Gager M. Post-traumatic stress disorder-related symptoms in relatives of patients following intensive care. Intensive Care Med. 2004;30(3):456-60.

3. Davydow DS, Gifford JM, Desai SV, Needham DM, Bienvenu OJ. Posttraumatic stress disorder in general intensive care unit survivors: a systematic review. Gen Hosp Psychiatry. 2008:30(5):421-34.

4. Davydow DS, Gifford JM, Desai SV, Bienvenu OJ, Needham DM. Depression in general intensive care unit survivors: a systematic review. Intensive Care Med. 2009;35(5):796-809.

5. Desai SV, Law TJ, Needham DM. Long-term complications of critical care. Crit Care Med. 2011;39(2):371-9.

6. Puntillo KA, Arai S, Cohen NH, Gropper MA, Neuhaus J, Paul SM, Miaskowski C. Symptoms experienced by intensive care unit patients at high risk of dying. Crit Care Med. 2010;38(11):2155-60.

7. Backman CG, Walther SM. Critical periods at the intensive care units are documented in diaries. Lakartidningen. 1999;96(5):468-70.

8. Jones C, Backman C, Capuzzo M, Egerod I, Flaatten H, Granja C, Rylander C, Griffiths RD, group R. Intensive care diaries reduce new onset post traumatic stress disorder following critical illness: a randomised, controlled trial. Crit Care. 2010;14(5):R168.

9. Knowles RE, Tarrier N. Evaluation of the effect of prospective patient diaries on emotional well-being in intensive care unit survivors: a randomized controlled trial. Crit Care Med. 2009;37(1):184-91.

10. Mcllroy PA, King RS, Garrouste-Orgeas M, Tabah A, Ramanan M. The effect of ICU diaries on psychological outcomes and quality of life of survivors of critical illness and their relatives: a systematic review and meta-analysis. Crit Care Med. 2019;47(2):273-9.

11. Kredentser MS, Blouw M, Marten N, Sareen J, Bienvenu OJ, Ryu J, Beatie BE, Logsetty S, Graff LA, Eggertson S, et al. Preventing posttraumatic stress in 
ICU survivors: a single-center pilot randomized controlled trial of ICU diaries and psychoeducation. Crit Care Med. 2018;46(12):1914-22.

12. Nielsen AH, Angel S, Egerod I, Lund TH, Renberg M, Hansen TB. The effect of family-authored diaries on posttraumatic stress disorder in intensive care unit patients and their relatives: a randomised controlled trial (DRIP-study). Aust Crit Care. 2019.

13. Garrouste-Orgeas M, Flahault C, Vinatier I, Rigaud JP, Thieulot-Rolin N, Mercier E, Rouget A, Grand H, Lesieur O, Tamion F, et al. Effect of an ICU diary on posttraumatic stress disorder symptoms among patients receiving mechanical ventilation: a randomized clinical trial. JAMA. 2019;322(3):229-39.

14. Sterne JA, Hernan MA, Reeves BC, Savovic J, Berkman ND, Viswanathan M, Henry D, Altman DG, Ansari MT, Boutron I, et al. ROBINS-I: a tool for assessing risk of bias in non-randomised studies of interventions. BMJ. 2016:355:14919.

15. Higgins JPT TJ, Chandler J, Cumpston M, Li T, Page MJ, Welch VA. Cochrane Handbook for systematic reviews of interventions version 6.0 (updated July 2019). Available from https://training.cochrane.org/handbook/current.

16. Viechtbauer W. Conducting meta-analyses in $\mathrm{R}$ with the metafor package. J Stat Softw. 2010;36(3):48.

17. Hartung J, Knapp G. A refined method for the meta-analysis of controlled clinical trials with binary outcome. Stat Med. 2001;20(24):3875-89.

18. IntHout J, loannidis JP, Borm GF. The Hartung-Knapp-Sidik-Jonkman method for random effects meta-analysis is straightforward and considerably outperforms the standard DerSimonian-Laird method. BMC Med Res Methodol. 2014;14:25.

19. Rover C, Knapp G, Friede T. Hartung-Knapp-Sidik-Jonkman approach and its modification for random-effects meta-analysis with few studies. BMC Med Res Methodol. 2015;15:99.

20. Chiolero A, Santschi V, Burnand B, Platt RW, Paradis G. Meta-analyses: with confidence or prediction intervals? Eur J Epidemiol. 2012;27(10):823-5.

21. IntHout J, loannidis JP, Rovers MM, Goeman JJ. Plea for routinely presenting prediction intervals in meta-analysis. BMJ Open. 2016;6(7):e010247.

22. RevMan Calculator - https://training.cochrane.org/resource/revmancalculator. Accessed 5 Aug 2019

23. Wan X, Wang W, Liu J, Tong T. Estimating the sample mean and standard deviation from the sample size, median, range and/or interquartile range. BMC Med Res Methodol. 2014;14:135.

24. Luo D, Wan X, Liu J, Tong T. Optimally estimating the sample mean from the sample size, median, mid-range, and/or mid-quartile range. Stat Methods Med Res. 2018;27(6):1785-805.

25. Estimating the sample mean and standard deviation from the sample size, median, range and/or interquartile range - http://www.comp.hkbu.edu. hk/ xwan/median2mean.html. Accessed 16 Aug 2019.

26. Akerman $\mathrm{E}$, Langius-Eklof $\mathrm{A}$. The impact of follow-up visits and diaries on patient outcome after discharge from intensive care: a descriptive and explorative study. Intensive Crit Care Nurs. 2018;49:14-20.

27. Backman CG, Orwelius L, Sjoberg F, Fredrikson M, Walther SM. Long-term effect of the ICU-diary concept on quality of life after critical illness. Acta Anaesthesiol Scand. 2010;54(6):736-43.

28. Garrouste-Orgeas M, Coquet I, Perier A, Timsit JF, Pochard F, Lancrin F, Philippart F, Vesin A, Bruel C, Blel Y, et al. Impact of an intensive care unit diary on psychological distress in patients and relatives*. Crit Care Med. 2012;40(7):2033-40.

29. Glimelius Petersson C, Ringdal M, Apelqvist G, Bergbom I. Diaries and memories following an ICU stay: a 2-month follow-up study. Nurs Crit Care. 2018;23(6):299-307.

30. Jones C, Backman C, Griffiths RD. Intensive care diaries and relatives' symptoms of posttraumatic stress disorder after critical illness: a pilot study. Am J Crit Care. 2012;21(3):172-6.

31. Svenningsen $H$, Tonnesen EK, Videbech $P$, Frydenberg $M$, Christensen $D$, Egerod I. Intensive care delirium - effect on memories and health-related quality of life - a follow-up study. J Clin Nurs. 2014;23(5-6):634-44.

32. Fukuda T, Inoue T, Kinoshita Y, Yukawa T. Effectiveness of ICU diaries: improving "distorted memories" encountered during ICU admission. Open $J$ Nurs. 2015;5:313-24.

33. Backman CG, Walther SM. Use of a personal diary written on the ICU during critical illness. Intensive Care Med. 2001;27(2):426-9.

34. Bergbom I, Svensson C, Berggren E, Kamsula M. Patients' and relatives' opinions and feelings about diaries kept by nurses in an intensive care unit: pilot study. Intensive Crit Care Nurs. 1999;15(4):185-91.

35. Engstrom A, Grip K, Hamren M. Experiences of intensive care unit diaries: 'touching a tender wound'. Nurs Crit Care. 2009;14(2):61-7.
36. Egerod I, Christensen D, Schwartz-Nielsen KH, Agard AS. Constructing the illness narrative: a grounded theory exploring patients' and relatives' use of intensive care diaries. Crit Care Med. 2011;39(8):1922-8.

37. Akerman E, Ersson A, Fridlund B, Samuelson K. Preferred content and usefulness of a photodiary as described by ICU-patients--a mixed method analysis. Aust Crit Care. 2013;26(1):29-35.

38. Perier A, Revah-Levy A, Bruel C, Cousin N, Angeli S, Brochon S, Philippart F, Max A, Gregoire C, Misset B, et al. Phenomenologic analysis of healthcare worker perceptions of intensive care unit diaries. Crit Care. 2013;17(1):R13.

39. Ewens B, Chapman R, Tulloch A, Hendricks JM. ICU survivors' utilisation of diaries post discharge: a qualitative descriptive study. Aust Crit Care. 2014; 27(1):28-35

40. Garrouste-Orgeas M, Perier A, Mouricou P, Gregoire C, Bruel C, Brochon S, Philippart F, Max A, Misset B. Writing in and reading ICU diaries: qualitative study of families' experience in the ICU. PLoS One. 2014;9(10):e110146.

41. Johansson M, Hanson E, Runeson I, Wahlin I. Family members' experiences of keeping a diary during a sick relative's stay in the intensive care unit: a hermeneutic interview study. Intensive Crit Care Nurs. 2015;31(4):241-9.

42. Nielsen AH, Angel S. Relatives perception of writing diaries for critically ill. A phenomenological hermeneutical study. Nurs Crit Care. 2016;21(6):351-7.

43. Ednell AK, Siljegren S, Engstrom A. The ICU patient diary-a nursing intervention that is complicated in its simplicity: a qualitative study. Intensive Crit Care Nurs. 2017:40:70-6.

44. Johansson M, Wahlin I, Magnusson L, Runeson I, Hanson E. Family members' experiences with intensive care unit diaries when the patient does not survive. Scand J Caring Sci. 2018;32(1):233-40.

45. Strandberg S, Vesterlund L, Engstrom A. The contents of a patient diary and its significance for persons cared for in an ICU: a qualitative study. Intensive Crit Care Nurs. 2018;45:31-6.

46. Nielsen AH, Angel S, Hansen TB, Egerod I. Structure and content of diaries written by close relatives for intensive care unit patients: a narrative approach (DRIP study). J Adv Nurs. 2019;75(6):1296-305.

47. Nielsen AH, Egerod I, Hansen TB, Angel S. Intensive care unit diaries: developing a shared story strengthens relationships between critically ill patients and their relatives: a hermeneutic-phenomenological study. Int J Nurs Stud. 2019;92:90-6.

48. Ullman AJ, Aitken LM, Rattray J, Kenardy J, Le Brocque R, MacGillivray S, Hull AM. Intensive care diaries to promote recovery for patients and families after critical illness: a Cochrane systematic review. Int J Nurs Stud. 2015; 52(7):1243-53

49. Egerod I, Bagger C. Patients' experiences of intensive care diaries--a focus group study. Intensive Crit Care Nurs. 2010;26(5):278-87.

50. Johansson M, Wahlin I, Magnusson L, Hanson E. Nursing staff's experiences of intensive care unit diaries: a qualitative study. Nurs Crit Care. 2019;24(6): 407-13.

51. O'Gara G, Pattison N. A qualitative exploration into the long-term perspectives of patients receiving critical care diaries across the United Kingdom. Intensive Crit Care Nurs. 2016;36:1-7.

52. Gjengedal E, Storli SL, Holme AN, Eskerud RS. An act of caring - patient diaries in Norwegian intensive care units. Nurs Crit Care. 2010;15(4):176-84.

53. Egerod I, Christensen D. Analysis of patient diaries in Danish ICUs: a narrative approach. Intensive Crit Care Nur. 2009:25(5):268-77.

\section{Publisher's Note}

Springer Nature remains neutral with regard to jurisdictional claims in published maps and institutional affiliations.

Ready to submit your research? Choose BMC and benefit from:

- fast, convenient online submission

- thorough peer review by experienced researchers in your field

- rapid publication on acceptance

- support for research data, including large and complex data types

- gold Open Access which fosters wider collaboration and increased citations

- maximum visibility for your research: over $100 \mathrm{M}$ website views per year

At $\mathrm{BMC}$, research is always in progress.

Learn more biomedcentral.com/submissions 